\title{
Kamu Yönetim Etkinliği ve Yolsuzluğun Doğrudan Yabancı Yatırımlar ile İlişkisinin İncelenmesi: E7 Ülkeleri Üzerine Bir Analiz
}

\author{
Arzu Dilaveroğlu ${ }^{1}$ ve İrfan Ersin ${ }^{2 *}$ \\ 1İstanbul Medipol Üniversitesi, İnsan ve Toplum Bilimleri Fakültesi, İstanbul, Türkiye; adilaveroglu@medipol.edu.tr \\ 2̇̇stanbul Medipol Üniversitesi, Sosyal Bilimler MYO, İstanbul, Türkiye; iersin@medipol.edu.tr \\ Orcid: 0000-0002-7850-8838 Orcid: 0000-0002-7407-3654 ${ }^{2}$ \\ ${ }^{*}$ Corresponding Author, e-mail: iersin@medipol.edu.tr
}

\begin{abstract}
Öz: Bir ülke ekonomisinin gelişimine katkı sağlayan unsurlardan bir tanesi yönetim ve yargı kurumlarının güçlülüğüdür. Yabancı sermayeye ihtiyaç duyan ülkelerin yabancı yatırımları çekebilmek için ekonomik göstergelerinin iyi olmasının yanında siyasal ve hukuki yapılanmalarının da sağlam olması gerekmektedir. Nitekim demokrasi, hukuk, yönetim gibi değişkenlerin sağlamlı̆̆ı ekonomide yabancıların güvenini kazanmalarına neden olacaktır. Bu durumun da uzun vadeli doğrudan yabancı yatırımları pozitif etkileyeceği düşünülmektedir. Bu çalışma, kamu yönetim etkinliği ve yolsuzluğun kontrolü ile doğrudan yabancı yatırımlar (DYY) arasındaki ilişkiyi incelemeyi hedeflemektedir. Çalışmada kapsam olarak gelişmekte olan ülkeleri temsil eden E7 ülkeleri (Türkiye, Çin, Hindistan, Brezilya, Rusya, Endonezya, Meksika) dikkate alınmış ve 2002-2018 yılları arası veriler Pedroni Eşbütünleşme yöntemi ile ampirik olarak test edilmiştir. Analiz sonuçlarına göre, kamu yönetiminin etkinliği ve yolsuzluğun kontrolü ile DYY arasında uzun dönemli ilişki tespit edilmiştir. Gelişmekte olan ülkeler, DYY için yönetim etkinliğini daha da şeffaflaştırarak ve yolsuzluk kontrollerini daha artırarak yabancı yatırımclara güven verebilir ve uzun dönemli yabancı yatırımları çekebilir.
\end{abstract}

Anahtar Kelimeler: Yönetişim Göstergeleri, Kamu Yönetimi Etkinliği, Yolsuzluk, DYY, E7 Ülkeleri.

\section{Investigation of The Relationship Between Public} Administration Efficiency and Corruption with FDI:

\section{An Analysis on E7 Countries}

\begin{abstract}
One of the factors that contribute to the development of a country's economy is the powerfulness of management and judicial institutions. In order to attract foreign investments, countries that need foreign capital need to have strong political and legal structures as well as good economic indicators. As a matter of fact, the soundness of variables such as democracy, law, and administration will cause foreigners to gain confidence in the economy. This situation is thought to affect long-term foreign direct investments positively. This study aims to examine the relationship between public administration effectiveness and control of corruption and foreign direct investment (FDI). For this purpose, E7 countries (Turkey, China, India, Brazil, Russia, Indonesia, Mexico) representing developing countries are investigated in the empirical analysis. In addition, data from 2002 to 2018
\end{abstract}


are utilized by using the Pedroni Cointegration method. The results of the analysis show that there is a long-term relationship between the effectiveness of public administration and the control of corruption with FDI, developing countries can give assurance to the foreign investors and attract long-term foreign investments, by making management effectiveness transparent and increasing corruption controls.

Keywords: Governance İndicators, Public Administration Effectiveness, Corruption, FDI, E7 Countries

\section{Giriş}

Bir ülke ekonomisinde doğrudan yabancı yatırımlar, ülkenin milli gelirinin artmasında önemli bir değişkendir. Özellikle yabancı sermayeye ihtiyaç duyan gelişmekte olan ülkeler için bu durum ciddi önem taşımaktadır. Gelişmekte olan ülkeler yabancı sermayeyi iki şekilde ülkelerine kazandırabilir. Bunlardan biri finansal piyasaları ve türev ürünleri kullanarak borçlanma kağıtları yoluyla, diğeri ise doğrudan ülkeye yapılan yatırımlarla söz konusu olabilmektedir [1]. Finansal piyasalar yoluyla gelen sermayenin geri ödenmesi faiz yoluyla söz konusu olduğu ve de finansal piyasalarda yabancı yatırımcı kısa vadeli fonlama yöntemlerini tercih ettiği için bu durum ülke ekonomilerinin borçlanmasını artırmaktadır. Ek olarak yabancı yatırımcılar, kısa vadede tasarruflarını hızlı bir şekilde geri çekebilmektedir. Nitekim bu durumda ülke ekonomileri, yabancı yatırımcıya güven verme noktasında siyasi ve ekonomi politikalarını doğru ayarlayabilmelidirler. Çünkü kısa vadeli fonların uzun vadede doğrudan yabancı yatırımlara çevrilebilmesi gelişmekte olan ülkelerin arzu ettiği bir konudur. Çünkü DYY, ülkede istihdama katkı sunmanın yanında ekonomik üretimin artışına da olanak sağlamaktadır [2].

Yabancıların doğrudan yatırım yapması için ülkelerde belli kriterler dikkate alınmaktadır. Bu kriterler iki önemli konuda ön plana çıkmaktadır. Bunlardan ilki ekonomik kriterler olup literatürde bu kriterler büyüme, enflasyon, işgücü maliyetleri, dışa açıklık oranı, kişi başına düşen CO2 emisyonu, Ar-Ge harcama oranı ve enerji kullanımı olarak sıralanmaktadır [3-5]. İkincisi ise siyasi kriterler olarak dikkate alınmakta ve bunlar da literatürde kamu yönetim etkinliği indeksi, ifade hakkı ve hesap verebilirlik indeksi, yolsuzluk kontrol indeksi, demokrasi indeksi ve politik istikrar göstergesi şeklinde ifade edilmektedir [6-8]. Ek olarak, doğrudan yabancı yatırımların en önemli belirleyicisi Hood ve Young [9] tarafından belirlenen kuruluş yeri teorisi içinde yer almaktadır. Söz konusu bu teoriye göre, DYY için işgücü maliyetleri, piyasa faktörleri, ticari engeller ve hükümet politikaları temel faktörler olarak gösterilmektedir. Bunun yanında doğrudan yabancı yatırımların arttırılmasında kamu yönetim etkinliğinin de önemli olduğunu ifade eden teoriler ürünün hayat devreleri teorisi [10] içselleştirme teorisi [11], oligopolistik tepki teorisi [12] ve eclectic teorisidir [13].

Ülke ekonomi yönetimlerinin vatandaşa karşı önemli sorumluluklarından biri de yolsuzluğu ortadan kaldırmaktır. Yolsuzluk, ekonomide bütçe üzerinde önemli bir etkiye sahip olmaktadır. Yolsuzluğun olduğu ülkelerde devlet giderleri artış göstermekte ve bu durum bütçe açı̆̆ını artırmaktadır. Bütçe açığı artışı da vergi ve enflasyon üzerinde olumsuz etkiye sahip olmaktadır. Yolsuzluğun iç ekonomik etkilerinin yanında diş ekonomi üzerinde de etkisi söz konusudur. Yolsuzluk, DYY'ti etkileyen önemli değişkenler arasında yer almaktadır. Wei (1997), yolsuzluğun DYY'yi olumsuz etkilediğini ve yatırımcı için görünmeyen ek bir vergi olarak görüldüğünü ifade etmektedir. Yolsuzluk hareketleri ile piyasadaki belirsizliğin arttığı ve bu durumun yabancı yatırımcıyı rahatsız ettiği belirtilmektedir. Yolsuzluğun olduğu bir ülkede, istikrarlı bir ekonomi oluşamamaktadır. Ek olarak, DYY'nin olumsuz etkilenmesi durumunda DYY ile birlikte gelen bilgi birikimi ve teknoloji de ekonomik büyümeye katk1 sunamayacaktır $[6,14]$.

Doğrudan yabancı yatırımlar ile kamu yönetim etkinliği ve yolsuzluğun kontrolü arasındaki ilişkiyi inceleyen çalışmamızda Gelişmekte olan ülkeleri temsilen E-7 ülkeleri dikkate alınmış ve 2002-2018 dönemi analiz edilmiştir. Yatay kesit bağımsızlığı ve homojenlik test sonuçları dikkate alınarak Pedroni Eşbütünleşme testinin kullanıldığı çalışmamızın ilk bölümünde doğrudan yabancı yatırımlar ile kamu yönetim etkinliği ve yolsuzluk kontrol değişkenleri hakkında bilgi verilirken, doğrudan yabancı yatırımları belirleyen faktörler üzerinde durulmuştur. İkinci bölümde konuyla ilgili literatür taraması yapılmış, üçüncü bölümde ise ampirik uygulamaya gidilmiştir. Son bölümde de sonuç ve değerlendirme yapılmıştır. 


\section{Literatür Taraması}

Literatür incelemesi kapsamında yönetişim göstergeleri ve DYY ilişkisini ampirik olarak analiz eden pek çok çalışma olduğu görülmektedir. Bu incelemeler kapsamında oluşturulan güncel literatüre ilişkin örnekler bu başlık altında özetlenmiştir. Söz konusu örnekler farklı dönem, ülke ve yöntemlerle yapılmış olmasına rağmen bu çalışmaların ampirik sonuçları büyük oranda benzerlik göstermektedir. Yolsuzluğun azaltılması ve kamu yönetim etkinliğindeki artış ile DYY arasında genel olarak pozitif ilişki olduğu görülmektedir. Bununla birlikte alan yazınında bu değişkenler arasında negatif ilişki olduğunu ortaya koyan çalışmalar da bulunmaktadır.

Gani [15] tarafından hazırlanan yönetişim göstergeleri ile doğrudan yabancı yatırım (DYY) arasındaki ilişkinin araştırıldığı çalışmada Asya, Latin Amerika ve Karayip bölgelerinden 17 ülkenin 1996, 1998, 2000 ve 2002 dönemleri, panel veri analizi yöntemi ile test edilmiştir. Çalışmada hukukun üstünlügü, yolsuzluğun kontrolü, düzenleyici kalite, devletin etkinliği ve siyasi istikrar ile DYY arasında pozitif ilişki olduğu sonucuna varılmıştır. Zeshan ve Talat'ın [16] Pakistan için yaptı̆̆ı çalışmada 1996-2010 yıllarına ait verileri ARMA ve normal en küçük kareler (EKK) regresyon teknikleri kullanarak analiz etmiş, ülkedeki DYY girişleri ile yönetişim göstergelerinin pozitif ve anlamlı bir ilişkiye sahip olduğu sonucuna ulaşmıştır. Bu sebepten dolayı yatırımcı girişlerini artırmak için yönetişim göstergelerinin iyileştirmek zorunluluğu üzerinde durulmuştur.

Zidi ve Ali [17] MENA bölgesindeki 11 ülke üzerine yaptığı panel veri çalışmasında, 1996-2014 dönemini analiz etmiş ve Rassal Etkiler Modelini kullanmışlardır. Analiz sonucunda yönetişim değişkeni ile DYY girişi arasında pozitif ilişki olduğu görülmüş, finansman akışlarından faydalanabilmek için yönetişimin geliştirilmesini sağlayacak politikaların hazırlanması gerekliliği üzerinde durulmuştur. Aynı bölge üzerinde çalışma yapan Şahin [18] 2002-2005 dönemine ait verileri panel regresyon ile test etmiş yönetişim kalitesinin ekonomik büyümeyi pozitif anlamda desteklendiği sonucuna ulaşılmıştır. Mengistu ve Adhikary [19], 15 Asya ülkesine ait 1996-2007 dönemi verilerini Uygulanabilir En Küçük Kareler (FGLS) yöntemi ile yönetişim göstergeleri ve DYY arasındaki ilişkiyi test etmek için kullanmıştır. Çalışma sonucunda DYY girişlerinde siyasi istikrar ve şiddetin olmaması, devletin etkinliği, hukukun üstünlüğü ve yolsuzluğun kontrolü göstergelerinin yatırım girişlerinin kilit belirleyicileri olduğunu bulgularına ulaşılmıştır.

Yolsuzluk ve demokrasi ile DYY arasındaki ilişkisini inceleyen Ay vd. [20], 10 gelişmekte olan ülkenin 1995-2003 dönemine ait verilerini panel FMOLS eşbütünleşme tahmincisi ve panel VEC nedensellik analiz yöntemlerini kullanarak analiz etmiştir. Yapılan çalışma sonucu yolsuzluk, demokrasi ve doğrudan yabancı yatırımların uzun dönemde eşbütünleşik olduğu bulgusuna ulaşılmıştır. Canare [21] tarafından yapılan çalışmada, Asya ve Pasifik bölgesindeki 46 ülke için 2006-2013 dönemi dikkate alınarak Genelleştirilmiş Momentler Yöntemi (GMM) ile analiz edilmiştir. Test sonuçları, yolsuzluğun doğrudan yabancı yatırım girişleri üzerinde olumsuz bir etkisi olduğunu göstermiştir. . Nur ve Dilber [22] tarafından 18 gelişmekte olan ülkeye ait 1996-2004 dönemine ait veriler panel regresyon yöntemi ile incelenmiştir. Yapılan çalışmada "yolsuzluk kontrolü, dışa açıklık oranı, teknoloji, toplam işgücü ve hukukun üstünlüğ̈̈" değişkenlerinin yatırımları pozitif etki ettiği ancak en güçlü değişkenin yolsuzluk kontrolü (yolsuzluk kontrolünün \%1 artırıldığında DYY miktarının \%0,89 arttığı görülmüştür) olduğu görülmüştür. 117 ülke üzerinde çalışma yapan Al-Sadig [23], 1984-2004 verilerini kapsayan dönemi panel regresyon yöntemi ile incelemiştir. Yolsuzluk düzeyindeki 1 birimlik bir artışın DYY girişlerini yaklaşık \%11 düzeyinde azaltacağını tespit etmiştir. Söz konusu çalışmada yolsuzluk ve DYY arasındaki bu negatif ilişkinin ortadan kaldırılmasında kurumların kalitesinin artırılmasının etkili olacağ vurgulanmıştır.

Epaphra ve Massawe ise [24], 5 Doğu Afrika Ülkesinde benzer bir çalışma gerçekleştirmiştir. Ülkelere ait 1996-2015 dönemini panel veri analiz yöntemi ile incelemiştir. Analiz sonucu ev sahibi ülkedeki yolsuzluk seviyesinin, DYY girişleri üzerinde olumsuz etki oluşturduğu ve bu nedenle ülkenin kurum kalitesi ve yolsuzluk kontrolünün yapılmasının, DYY girişlerini artırmak için önemli bir strateji olacağı sonucuna ulaşmıştır. Farklı gelir gruplarındaki ülkeleri (Düşük, alt-orta, üst-orta ve yüksek gelirli ülkeler) 1996-2016 dönem kapsamında, GMM yöntemi ile inceleyen Sabır vd. [25], kurumsal kalitenin tüm ülke gruplarında, DYY üzerinde olumlu bir etki yarattığı sonucuna ulaşmıştır. . Kurumsal kalite ve yatırımlar arasındaki ilişkinin test edildiği başka bir çalışma Masron ve Abdullah [26] tarafından ele alınmıştır. ASEAN ülkeleri örneği üzerinden ele alınan çalışmada 1996-2008 yıllarına ait veriler panel 
veri analizi yöntemi ile incelenmiş, ülkeye yapılan yabancı yatırımların devamlılığının sağlanması ve yeni yatırımların çekilmesi için kurumsal kalitenin artırılması gerektiği sonucuna ulaşılmıştır.

Türkiye örneği üzerinde durumu test eden Özşahin [27] ise 1998-2014 dönemi verilerini sınır testi ve ARDL yöntemi ile ele almıştır. Çalışmada kaliteli kurumsal yapının yabancı yatırım hacmini artıracağı ve ülkedeki oynaklığını azalttığı bulgusu elde edilmiştir. Bu sonucu destekleyen başka bir çalışma Méon ve Sekkat [28] tarafından yapılmıştır. 96 ülkenin 90'lar dönemini kapsayan ve en küçük kareler yöntemi ile gerçekleştirilen analiz sonucu kurumsal kalite artışı ve DYY arasında pozitif ilişki olduğu ortaya konulmuştur. Saidi vd. [29] tarafından gelişmiş ve gelişmemiş 20 ülkelerin 1998-2011 sürecini kapsayan ve panel veri analiz yöntemi ile gerçekleştirilen çalı̧̧mada ise, yabancı yatırımcıların yurtdışındaki yatırım seçimlerinde politik istikrar ve düzenleyici kalite ile ilgilendikleri bulgusuna ulaşılmıştır.

Shah ve Afridi [30] SAARC ülkelerinin 2006-2014 dönemine ait verileri panel veri analizi ile incelemiştir. Elde ettiği sonuçlara göre yatırımlara ev sahipliği yapacak ülkenin kurumsal kalitesini artırması pazara girişlerin kolaylaştırılması, çok uluslu şirketlerin yatırımlarını artırmasını sağlarken, yolsuzluğun yaygınlaşmış olması yatırımcılar açısından ek maliyet oluşturacağı için yatırım yapmaktan kaçınmalarına neden olmaktadır.

Genel olarak bakıldığında kamu yönetimi etkinliğinin düşük olması ve yolsuzluk, yatırım kararları üzerinde bir bozulma faktörü oluşturmaktadır. Ancak literatürde bunun aksini iddia eden çalışmalarda bulunmaktadır. Bellos ve Subasat [31] 14 geçiş ülkesine ait verileri panel veri analizi yöntemi ile incelemiş, çalışmada yönetişim eksikliğinin DYY caydırmadığını aksine yönetişim düzeyi yüksek olan ülkelerden yönetişim anlayışının zayıf olduğu ülkelere doğru yatırım yapma eğiliminin arttığ1 bulgusuna ulaşmıştır. Luu vd. [32] tarafından 131 ülkede GMM, iki aşamalı en küçük kare tahmincisi ve iki aşamalı sistem GMM tahmincisi yöntemi ile yolsuzluk ve DYY arasındaki ilişkinin incelediği çalışmada ise birbiri ile çelişen iki bulguya ulaşılmıştır. Bunlardan ilki yolsuzluğun sınır ötesi birleşme ve satın alma işlemlerinde caydırıcı etki yaratmasıdır. İkincisi ise yeni yatırımların yapılmasında bürokratik prosedürleri azaltmak ve pazara girişi hızlandırmak için yolsuzluk ortamından yararlanıldığıldır.

Cuervo-Cazurra'nın [33] 2006 yılı için yolsuzluk ve yatırım ilişkisi üzerine yaptığı çalışmada tüm yabancı yatırımcıların yolsuzluktan aynı şekilde etkilenmediğini savunmaktadır. Elde ettiği analiz sonucunda rüşvet yasalarına sahip ülkelerden gelen yatırımcıların, yüksek yolsuzluk olan ülkelere yatırımlarını sınırlandırdığı görülmektedir. Kendi ülkesinde yüksek yolsuzluk düzeyine sahip olan ülkelerdeki yatırımcıların ise yolsuzluğun yüksek olduğu ülkelere yatırımlarını sınırlandırmak yerine yatırım yapmak için bu tip ülkeler aradığı görülmüsştür. Bu durum farklı ülkelerden gelen yatırımcıların yolsuzluk karşısında farklı tavırlar sergilediğini göstermektedir.

Yolsuzluk ve yatırımlar arası ilişkinin bölgelere göre farklılık göstereceğini ortaya koyan başka bir çalışma Asiedu ve Freeman [33] tarafından hazırlanmıştır. 81 ülke 10.322 firma üzerinde yaptığ1 çalışmada geçiş ülkeleri için yolsuzluk yatırımın en önemli belirleyici iken Latin Amerika ve Sahra Altı Afrika şirketleri için etkisinin olmadığ 1 tespit edilmiştir. Eren ve Künü [34] ise Ortak İlişkili Etkiler Modeli (CCE) yöntemini kullanarak E7 ülkeleri üzerinde yaptığı çalışmada yolsuzluk algısındaki iyileşmenin Brezilya ve Çin'in büyümesi üzerindeki etkisinin pozitif, Hindistan ve Rusya üzerinde negatif etki yarattığı bulgusuna ulaşmıştır.

Yapılan literatür taraması sonucunda çalışmamız yolsuzluk kontrolü ve kamu yönetim etkinliğinin E7 ülkelerinde doğrudan yabancı yatırımlarla ilişkisini analiz ederek literatüre katkı sağlamayı hedeflemektedir.

\section{Ampirik Uygulama}

\subsection{Veri Seti ve Yöntem}

Kamu yönetim ve yolsuzluk endekslerinin doğrudan yabancı yatırım ile ilişkisini ele alan bu çalışma E7 ülkelerini analiz etmektedir. Çalışmamızda 2002-2018 dönemi yıllık olarak ele alınmıştır. Çalışmada kullanılan değişkenlerin tanım ve kaynakları Tablo 1'de verilmiştir. Söz konusu tabloda "kamu" değişkeni kamu yönetim etkinliğini temsil etmektedir. Dünya bankası kaynağından elde edilen bu değişken, kamu yönetim etkinliği endeksinden oluşmaktadır. Kamu yönetim etkinliği de kamu hizmetlerinin kalite algısı, vatandaşlara hizmet kalitesi ve siyasi baskılarda bağımsızlık derecesi, 
politika oluşturma ve uygulama kalitesi ve hükümetin bu politikalara bağlllı̆̆ının güvenilirliği kısımlarından oluşmaktadır. Kamu yönetim etkinlik endeksi, $-2,5$ ile $+2,5$ arasında bir değer almaktadır. Kamu yönetim etkinliğinin çok düşük olması $-2,5$ ile, çok güçlü olması ise $+2,5$ ile gösterilmektedir. Diğer bir değişken olan "yols" ise yolsuzluk kontrol endeksini temsil etmektedir. Yolsuzluğun kontrolü de hem küçük hem de büyük yolsuzluk biçimleri de dahil olmak üzere kamu iktidarının özel kazanç için ne ölçüde kullanıldığına dair algılardan ve ayrıca devletin seçkinler ve özel çıkar guruplarının etkisinde olma durumlarından oluşmaktadır. Dünya bankası verilerinden elde edilen yolsuzluğun kontrol endeksinde en zayıf gösterge $-2,5$, en güçlü gösterge ise $+2,5$ ile temsil edilmektedir. Yani $-2,5$ verisi söz konusuysa yolsuzluk kontrolünün çok zayıf olduğu anlaşılmaktadır. Tablo1'de ayrıca "dyy" değişkeni doğrudan yabancı yatırımları temsil etmektedir. Dünya bankası kaynağından elde edilen bu değişken, GSYİH'nın oranı olarak dikkate alınmıştır [36].

Tablo 1. Değişken Tanımları

\begin{tabular}{lll}
\hline Değişken Adı & Tanımı & Kaynak \\
\hline kamu & Kamu yönetiminin etkinliği endeksi & World Bank ${ }^{1}$ \\
yols & Yolsuzluğun kontrolü endeksi & World Bank $^{2}$ \\
dyy & $\begin{array}{l}\text { Doğrudan Yabancı Yatırımların GSYH içindeki } \\
\text { payı (\%) }\end{array}$ & World Bank $^{3}$ \\
\hline
\end{tabular}

Çalışmada değişkenler arasında eşbütünleşme testi yapabilmek için öncelikle değişkenlerde yatay kesit bağımlılığ1 olup olmadığ1 kontrol edilecektir. Daha sonra bağımlı ve bağımsız değişkenler arasında homojenlik testi uygulanacaktır. Bu iki test sonrasında birim kök ve eşbütünleşme testine geçilecektir.

\subsection{Yatay Kesit Bă̆ımlılı̆̆ı Testi}

Panel veri analizlerinde sahte regresyon sorununu ortadan kaldırmanın önemli bir yöntemi kullanılan değişkenlerin durağanlık seviyelerinin bilinmesidir. Durağanlık seviyelerinin de belirlenebilmesi için uygun panel birim kök testinin seçilmesi gerekmektedir. Panel birim kök testleri yatay kesit bağımsızlığı ve homojenlik testlerine göre birinci nesil birim kök ve ikinci nesil birim kök testleri olmak üzere iki ayrı alana ayrılmaktadır. Bu sebeple değişkenlerin yatay kesit bağımsızlık testleri önem arz etmektedir [37].

Yatay kesit bağımsızlı̆̆1 testi, panelde yer alan değişkenlere gelen herhangi bir şoktan analize tabi tutulan ülkelerin etkilenme derecelerinin aynı olması ve ilgili değişkenler dikkate alınarak ülkelerde meydana gelen bir birim şokun diğer ülkeleri etkilememesi anlamını taşımaktadır. Küreselleşme olgusu ile günümüzde özellikle ekonomik değişkenlerde meydana gelen şoklar diğer ülkeleri etkileyebilmektedir. Bu sebeple panel testlerde yatay kesit bağımsızlığı testi ön plana çıkmaktadır. Yatay kesit bağımsızlığ 1 testinde kalıntılar arası korelasyon sıfır olarak varsayılmakta ve birimler arası korelasyonun anlamlılığ test edilmektedir [38]. Sabit etkili model içinde yatay kesit bağımlılığ testi Lagrange Çarpanı ile işlem görmektedir. T gözlem sayısını $\mathrm{N}$ ise yatay kesit sayısını temsil etmekte ve yatay kesit bağımlılık testlerinde zaman ve yatay kesit boyutu önem arz etmektedir. Şöyle ki, T>N olduğu durumda Breusch-Pagan [39] tarafından geliştirilen Lagrange Multiplier (LM) testi, N>T olduğu durumda Peseran [40] tarafından geliştirilen Peseran CD testi ve her iki boyutun büyük olması durumunda Pesaran vd. [41] önerdiği CDLMadj testleri kullanılabilmektedir [42].

Tablo 2. Yatay Kesit Bağımsızlığı

\begin{tabular}{lccc}
\hline Test & $\begin{array}{c}\text { dyy } \\
\text { (Olasılık) }\end{array}$ & $\begin{array}{c}\text { kamu } \\
\text { (Olasılık) }\end{array}$ & $\begin{array}{c}\text { yols } \\
\text { (Olasıllk) }\end{array}$ \\
\hline Breusch-Pagan LM & 0.0625 & 0.1554 & 0.4816 \\
Pesaran scaled LM & 0.0681 & 0.3171 & 0.9547 \\
Bias-corrected scaled LM & 0.0636 & 0.4431 & 0.7717 \\
\hline
\end{tabular}

\footnotetext{
${ }^{1}$ https://info.worldbank.org/governance/wgi/Home/Reports Erişim Tarihi: 07.01.2020

${ }^{2}$ https://info.worldbank.org/governance/wgi/Home/Reports Erişim Tarihi: 07.01.2020

${ }^{3}$ https://data.worldbank.org/indicator/BX.KLT.DINV.WD.GD.ZS Erişim Tarihi:07.01.2020
} 


\begin{abstract}
Pesaran CD
0.0885

0.9173

0.0320

Çalışmamızda yatay kesit bağımsızlığı testine göre yolsuzluğun kontrolü değişkeni (CORRUPTİON) Peseran CD testi haricinde diğer tüm değişkenlerin olasılık sonuçları 0.05'ten büyük çıkmıştır. Bu sonuçlara göre söz konusu değişkenlerde yatay kesit bağımsızlığı tespit edilmiştir. Bu durumda değişkenlerin durağanlık testleri için birinci nesil birim kök testleri tercih edilebilir. Ancak kesin sonuca varabilmek için değişkenlere homojenlik testinin de uygulanması gerekmektedir.
\end{abstract}

\title{
3.3. Homojenlik Testi
}

Panel veri analizlerinde ülkelerin birinde meydana gelen bir gelişme veya değişme durumunun diğer ülkelerde aynı etkiyi gösterme durumu homojenlik olarak ifade edilmektedir. İktisadi olarak ülkeler birbirine benziyorsa katsayılar homojen, farklılık arz ediyorsa katsayılar heterojen bir görünüm sergilerler. Homojenlik testi, değişkenler için uygulanacak olan birim kök ve eşbütünleşme testlerinin hangilerinin tercih edileceği noktasında bilgi vermektedir.

Çalışmamızda homojenlik testi için Hisao [43] testi tercih edilmiştir. Hisao [43] testi, H1, H2 ve H3 olmak üzere üç farklı hipotez altında çalışmaktadır. Bu üç farklı hipoteze göre H1 için boş hipotez katsayıların homojen olduğu belirtilirken, H1 için alternatif hipotez katsayıların heterojen olduğu üzerinedir. H2 için boş hipotez katsayıların homojen olduğunu belirtirken, alternatif hipotezin heterojen olduğunu göstermektedir. H3 için ise boş hipotez katsayıların homojen olduğu ve alternatif hipotezde katsayıların kısmen heterojen olduğu ifade edilmektedir [44].

Tablo 3. Homojenlik Test Sonuçları

\begin{tabular}{ccc}
\hline Hipotez & F-Stat & Olasılık \\
H1 & 0.434531 & 0.976359 \\
H2 & 0.593069 & 0.842615 \\
H3 & 0.123301 & 0.993314 \\
\hline
\end{tabular}

Homojenlik test sonuçlarına göre, homojenliğin kabul edildiği üç hipotezde de \%5 anlamlılık düzeyinde boş hipotez kabul edilmekte ve katsayıların homojen olduğu anlaşılmaktadır. Bu sonuçlardan yola çıkarak çalışmamızda yatay kesit bağımsızlığı ve homojenlik varsayımı altında birinci nesil birim kök testleri ve birinci nesil eş bütünleşme testleri kullanılacaktır.

\subsection{Birim Kök Testi}

Panel veri analizlerinde birim kök test uygulamaları için Genişletilmiş Dickey-Fuller (ADF) testi, en temel testler arasında yer almaktadır. Söz konusu bu testte değişkenlerin durağanlığının oluşabilmesi için zaman serisinin ortalama ve varyansının dönem içinde değişmemesi ve iki dönem arasındaki kovaryansının uzaklığa bağlı olarak hesaplanması gerekmektedir. Aşağıda verilen Denklem 1'de de sabit parametre modele dahil edilmiş ve $\varepsilon_{i t}$ hata süreci, değişkenler arasında bağımsız olarak dağılım göstermektedir. Birim kök test hipotezi aşağıdaki denklemde $\rho$ üzerine kuruludur. Ho: $\rho=0$ kabul edilirse serinin birim kök içerdiği ve durağan olmadığı, reddedilirse serinin birim kök içermediği ve durağan olduğu anlaşılır. Seri birim kök içerdiğinde serinin farkı alınarak durağan hale gelmiş olur [4548].

$$
\Delta y_{i t}=\alpha_{0 i}+\rho y_{i t-1}+\sum_{i=1}^{k} p_{i} \Delta y_{i t-1}+\varepsilon_{i t}
$$

Panel birim kök testlerinde ADF testi temel teşkil etmektedir. Literatürde birinci nesil panel birim kök testlerinde yaygin olarak Levin, Lin ve Chu [49], Im, Pesaran ve Shin [50], Maddala ve Wu [51], Choi'nin [52] çalışmaları genel olarak kabul görmüştür [53-56]. Çalışmamızda da literatürde yaygın olarak kullanılan bu yöntemler dikkate alınmıştır. Kamu yönetim etkinliği, yolsuzluğun kontrolü ve doğrudan 
yabancı yatırım değişkenlerinin birim kök test sonuçları aşağıda Tablo 4'te verilmiştir. Söz konusu tabloda kamu yönetim etkinliği değişkeni (kamu) tüm kriterlerde düzeyde durağan olarak tespit edilememiştir. Serilerin durağan hale gelmeleri için birinci farkları alınmış ve bu değişken LLC hariç diğer yöntemlerde birinci farkta durağan kabul edilmiştir.

Tablo 4. Birim Kök Test Sonuçları

\begin{tabular}{|c|c|c|c|c|}
\hline \multicolumn{5}{|c|}{ Kamu Yönetim Etkinliği (kamu) } \\
\hline & \multicolumn{2}{|c|}{ Sabitli ve Trendli } & \multicolumn{2}{|c|}{ Sabitli } \\
\hline & t- istatistiği I(0) & Olasılık I(0) & t-istatistiği I(1) & Olasılık I(1) \\
\hline Levin, Lin \& Chu & 1.48486 & 0.9312 & -1.23584 & 0.1083 \\
\hline Im, Pesaran and Shin W-stat & 1.58506 & 0.9435 & -2.66700 & $0.0038^{*}$ \\
\hline ADF - Fisher Chi-square & 7.08627 & 0.9313 & 29.9318 & $0.0078^{*}$ \\
\hline PP -Fisher Chi-square & 9.07633 & 0.8261 & 72.9232 & $0.0000^{*}$ \\
\hline \multicolumn{5}{|c|}{ Yolsuzluk Kontrolü (yols) } \\
\hline & \multicolumn{2}{|c|}{ Sabitli ve Trendli } & \multicolumn{2}{|c|}{ Sabitli } \\
\hline & t-istatistiği I(0) & Olasılık I(0) & t-istatistiği I(1) & Olasılık I(1) \\
\hline Levin, Lin \& Chu & -1.18212 & 0.1186 & -2.00477 & $0.0225^{* *}$ \\
\hline Im, Pesaran and Shin W-stat & 1.04913 & 0.8529 & -2.76823 & $0.0028^{*}$ \\
\hline ADF - Fisher Chi-square & 10.6731 & 0.7115 & 31.9974 & $0.0040^{*}$ \\
\hline PP - Fisher Chi-square & 14.5168 & 0.4120 & 79.2928 & $0.0000^{*}$ \\
\hline & \multicolumn{2}{|c|}{ Doğrudan Yabancı Yatırım (dyy) } & \multirow{2}{*}{\multicolumn{2}{|c|}{ Sabitli }} \\
\hline & Sabitli ve & Trendli & & \\
\hline & t-istatistiği I(0) & Olasılık I(0) & t-istatistiği I(1) & Olasılık I(1) \\
\hline Levin, Lin \& Chu & -3.72582 & $0.0001^{*}$ & -6.25102 & $0.0000^{*}$ \\
\hline Im, Pesaran and Shin W-stat & -1.34482 & $0.0893^{* * *}$ & -5.31681 & $0.0000^{*}$ \\
\hline ADF - Fisher Chi-square & 19.9996 & 0.1302 & 53.8074 & $0.0000^{*}$ \\
\hline PP - Fisher Chi-square & 41.3036 & $0.0002^{*}$ & 106.184 & $0.0000^{*}$ \\
\hline
\end{tabular}

Not: $* * *$ ve $* * *$ simgeleri sirasıyla $\% 1, \% 5$ ve $\% 10$ anlamlılık düzeylerini temsil etmektedir.

Yolsuzluğun kontrolü (yols) değişkeni birim kök testine tabi tutulduğunda ise düzeyde tüm yöntemlerde durağanlık söz konusu olmamıştır. Değişkenin durağan hale gelmesi için birinci fark alınmıştır. Son olarak doğrudan yabancı yatırım (dyy) değişkeninin de durağanlığı düzeyde kontrol edilmiş LLC'de \%1 anlamlılık düzeyinde, PP-Fisher'de \%1 anlamlılık düzeyinde ve IPS'de \%10 anlamlılık düzeyinde durağan kabul edilmiştir. Söz konusu değişkenin birinci farkı alınmış ve birinci farkta tüm yöntemlerde durağanlık söz konusu olmuştur.

\subsection{Pedroni Eşbütünleşme Testi}

Eşbütünleşme testi, iki değişken arasında uzun dönemde ilişkinin var olup olmadığı hakkında bilgi veren bir yöntemdir. Engle ve Granger [57] tarafından literatüre kazandırılan söz konusu bu test, zaman seri analizlerinde çokça kullanılmıştır. Eşbütünleşme testini panel olarak geliştiren Pedroni [58] ise, eşbütünleşme vektöründe hetorojenliğe izin vermiş, sabit ve dinamik etkilerin paneldeki kesitler arasında farklı olmasına yol açmıştır. Aşağıda Denklem 2'de Pedroni eşbütünleşme modeli verilmiştir. Denklem $2^{\prime} \mathrm{de}^{4}$ y bağımlı değişken, $\mathrm{x}$ ise bağımsız değişken olarak yer almaktadır [59].

\footnotetext{
4 Denklemde yer alan T zaman serisinde gözlem sayısını, N yatay kesitlerin toplam sayısını ve M de modeldeki değişken sayısını temsil eder. $\mathrm{N}$ kadar farklı kesit olması sebebiyle, her kesit içinde $\mathrm{M}$ tane değişken ve $\mathrm{N}$ tane farklı
} 


$$
\begin{gathered}
y_{i t}=\alpha_{i}+\delta_{i} t+\beta_{1 i} X_{2 i t}+\beta_{2 i} X_{2 i t}+\cdots+\beta_{M i} X_{M i t}+e_{i t} \\
\mathrm{t}=1, \ldots \ldots \mathrm{T}, i=1, \ldots \ldots \mathrm{N}, m=1, \ldots \ldots, \mathrm{M}
\end{gathered}
$$

Söz konusu modelde y ve x arasında uzun dönemli ilişkinin var olabilmesi için $e_{i t}$ hata teriminin durağan olması beklenir. Eğer hata terimi durağansa o zaman y ve $\mathrm{x}$ arasında uzun dönemli bir ilişki tespit edilir. Pedroni paneli eşbütünleşme analizinde, Panel v-İstatistiği, Panel rho-İstatistiği, Panel PP-İstatistiği, Panel ADF-İstatistiği, Grup rho-İstatistiği, Grup PP-İstatistiği ve Grup ADFİstatistiği olmak üzere 7 farklı test bulunmaktadır. Eşbütünleşme sonuç değerlendirmesi yapılırken söz konusu bu 7 testin 4'ünde $t$ istatistik anlamlılığı 0.05 'in altında gerçekleşirse değişkenler arasında eşbütünleşik ilişki olduğu varsayılır [60].

Doğrudan yabancı yatırımlar ile kamu yönetim etkinliği ve yolsuzluğun kontrolü arasındaki Pedroni eşbütünleşme test sonuçları Tablo 3’de verilmiştir. Söz konusu tabloya göre doğrudan yabancı yatırımlar ile kamu yönetim etkinliği arasındaki ilişkide Panel v- istatistik değeri dışında diğer tüm kriterlerde \%1 anlamlılık düzeyinde ilişki kabul edilmiştir. Bu sonuçlara göre doğrudan yabancı yatırımlar ile kamu yönetim etkinliği arasında uzun dönemli ilişkinin olduğu söylenebilir. Doğrudan yabancı yatırımlar ile yolsuzluğun kontrolü arasındaki ilişki sonuçlarında da Panel vistatistik değeri dışında diğer tüm kriterlerde \%1 anlamlılık düzeyinde ilişki kabul edilmiştir. Dolayısıyla doğrudan yabancı yatırımlar ile yolsuzluğun kontrolü arasında da uzun dönemde ilişkinin olduğunu söylemek mümkündür.

Tablo 3. Pedroni Eşbütünleşme Test Sonuçları

\begin{tabular}{lcc}
\hline \multirow{2}{*}{ Test Yöntemi } & $\begin{array}{c}\text { Doğrudan Yabancı Yatırım ile Kamu } \\
\text { Yönetim Etkinliği İlişkisi }\end{array}$ & $\begin{array}{c}\text { Doğrudan Yabancı Yatırım ile } \\
\text { Yolsuzluğun Kontrolü İlişkisi }\end{array}$ \\
\cline { 2 - 3 } Panel v-Statistic & $\begin{array}{c}\text { Olasılık } \\
\text { Olasılık }\end{array}$ & 0.8673 \\
Panel rho-Statistic & 0.8262 & $0.0000^{*}$ \\
Panel PP-Statistic & $0.0000^{*}$ & $0.0000^{*}$ \\
Panel ADF-Statistic & $0.0000^{*}$ & $0.0000^{*}$ \\
Group rho-Statistic & $0.0000^{*}$ & $0.0004^{*}$ \\
Group PP-Statistic & $0.0011^{*}$ & $0.0000^{*}$ \\
Group ADF-Statistic & $0.0000^{*}$ & $0.0000^{*}$ \\
\hline
\end{tabular}

Not: ${ }^{* *}$ ve ${ }^{* * *}$ simgeleri sırasıyla $\% 1, \% 5$ ve $\% 10$ anlamlılık düzeylerini temsil etmektedir.

Çalışmamızın bulguları ile literatürdeki sonuçlar karşılaştırıldığında Gani [15], Zeshan ve Talat'ın [16] , Zidi ve Ali [17], Mengistu ve Adhikary [19], Ay vd. [20], Canare [21], Al-Sadig [23], Epaphra ve Massawe ise [24], ve Özşahin'in [27] çalışmaları ile benzer sonuçlara ulaşıldığı anlaşılmıştır.

\section{Sonuç ve Tartışma}

Yolsuzluk "emanet edilen gücün özel kazanç için kötüye kullanılması" şeklinde tanımlanmaktadır. Politik, sosyal ve çevresel açıdan pek çok açıdan olumsuz sonuçlara sebep olan yolsuzluk, ekonomik açıdan adil piyasa yapılanmasını, rekabet ortamını ve yatırımları engelleme gibi durumların ortaya çıkmasına sebep olmaktadır. Birleşmiş Milletler tarafından hazırlanan "Yolsuzlukla Mücadele

denklem söz konusu olacaktır. $\beta_{1 i}, \beta_{2 i} \ldots \ldots \ldots \beta_{M i}$ eğim katsayılarını gösterir ve bu katsayılar yatay kesitler arası değişebilmektedir. $\alpha_{i}$ simgesi de yatay kesitlerde farklı sabit etki parametresi olarak ifade edilir. (Kılıç ve Aslan, 2017). 
Sözleşmesi" yolsuzluğu, haksız zenginleşmeye neden olan demokratik kurumlara ve ulusal ekonomilere zarar veren uluslararası bir mesele olarak ele almaktadır. Nitekim bu sözleşme ülkeler arası iş birliği gerekçesi ile hazırlanmıştır [61]. Bu meselenin önlenmesi noktasında ise kamu sektörünün verimlilik, etkinlik ve saydamlığının artırması için önleyici tedbirler konusuna özel önem verilmiştir Yolsuzluktan kaynaklı belirsizlik ve rüşvet gibi risklerin azaltılması ve yatırımcıların bürokratik işlemlerinde ortaya çıkabilecek zaman ve maliyet kayıplarının ortadan kaldırılabilmesi noktasında kamu yönetiminin etkinliğinin artırılması gerekmektedir.

Çalışmamızda gelişmekte olan ülkeleri temsilen E-7 ülkelerinde doğrudan yabancı yatırımlar ile kamu yönetim etkinliği ve yolsuzluğun kontrolü arasındaki ilişki ele alınmıştır. Çalışma sonucunda gelişmekte olan ülkelerde kamu yönetim etkinliğinin ve yolsuzluğun kontrol derecesinin doğrudan yabancı yatırımları çekmede önemli değişkenler olduğu görülmüştür. Dolayısıyla gelişmekte olan ülkeler doğrudan yabancı yatırımları kazanmak için kamu yönetiminde vatandaşların siyasi baskılara karşı bağımsızlık düzeyleri, kamu hizmet kalitesi ve politika oluşturmada siyasi bağımsızlık endeksleri önemli gözükmektedir. Bunun yanında gelişmekte olan ülkelerin yolsuzluğun kontrolünde şeffaf hareket etmesi ve bunun için gerekli yasal düzenlemeleri ve denetim mekanizmasının işleyişinin güçlendirilmesi gibi konular üzerinde durması önem arz etmektedir.

Bu çalışmada E-7 ülkeleri dikkate alınarak doğrudan yabancı yatırımlar ile kamu yönetim etkinliği ve yolsuzluk kontrolü arasındaki ilişki incelenmiştir. Diğer araştırmacılara da E-7 ülkeleri için doğrudan yabancı yatırımlar ile ifade hakkı ve hesap verebilirlik indeksi, demokrasi indeksi ve politik istikrar göstergesi arasındaki ilişkinin incelenmesi öneri olarak sunulmaktadır.

Yazar Katkıları: Bu çalışmada giriş ve sonuç bölümü ortak yapılmış, literatür bölümü A.D. tarafından hazırlanmıştır. Makalenin uygulama kısmı ve yorumlanması İ.E tarafından yapılmıştır.

Finansman: Bu çalışma için herhangi bir finansal kaynak sağlanmamıştır.

Çıkar Çatışması: Yazarlar herhangi bir çıkar çatışması olmadığını beyan etmemektedir.

\section{Kaynakça}

[1] Özcan, Burcu; Arl, Ayşe. Doğrudan Yabanci Yatirimlarin Belirleyicileri Üzerine Bir Analiz: Oecd Örneği. Ekonometri Ve İstatistik E-Dergisi, 2010, 12: 65-88.

[2] Nur, Hayriye Başçı; Dilber, İlkay. Gelişmekte olan ülkelerde doğrudan yabancı yatırımları belirleyen temel unsurlar. Dokuz Eylül Üniversitesi İktisadi İdari Bilimler Fakültesi Dergisi, 2017, 32.2: 15-45.

[3] Başar, Selim, et al. Yolsuzlukların Doğrudan Yabancı Yatırımlar (Dyy) Üzerine Etkileri. Iktisat Isletme ve Finans, 2004, 19.222: 66-76.

[4] Yorulmaz, Özlem; Yakut, Selay Giray; Gacar, Burcu Kocarik. Doğrudan Yabancı Yatırımları Etkileyen Faktörlerin Çok Değişkenli İstatistiksel Yöntemler ile İncelenmesi. Uluslararası İnsan Çalışmaları Dergisi, 2018, 1.2: 157-171.

[5] Yaylali, Muammer; Karaca, Zeynep. Türkiye'de Araştırma Geliştirme Harcamaları ile Doğrudan Yabancı Yatırım İlişkisi: Sınır Testi Yaklaşımı. Çukurova Üniversitesi İktisadi ve İdari Bilimler Fakültesi Dergisi, 2017, 18.1.

[6] Aydoğuş, İsmail; Kutlu, Erol; Yildirim, Selim. Yolsuzluk Ve Doğrudan Yabanci Yatirimlar. Afyon Kocatepe Üniversitesi İktisadi Ve İdari Bilimler Fakültesi Dergisi, 2005, 7.2: 1-21.

[7] Tanrikulu, Faik. Impact Of International Migration On Patents, Innovation, Economy And Business Strategy. In: Strategic Outlook For Innovative Work Behaviours. Springer, Cham, 2020. P. 221-234. 
[8] Da Silveira, Eduarda Martins Correa; Dias, Jorge Augusto. The determinants of foreign direct investment in Brazil: empirical analysis for 2001-2013. COMMISSION FOR LATIN AMERICA AND THE CARIBBEAN, 2017, 171.

[9] Hood, Neil; Young, Stephen. The economics of multinational enterprise. Longman, 1979.

[10] Vernon, Raymond. Storm over the Multinationals. Harvard University Press, 1977.

[11] Buckley, Adrian. Multinational Finance, Fourth Edition, Prentice Hall, New Jersey, 2000

[12] Dunning, John H. Fdi, globalisation and development: some implications for the Korean economy and Korean firms. Journal of Interna-tional Business and Economics, 2006, 7.1: 1-19.

[13] Aydın, Nurhan. Uluslararası doğrudan yatırımlar ve ortak girişimler: joint ventures. TC Anadolu Üniversitesi, 1997.

[14] Wei, Shang-Jin. How taxing is corruption on international investors?. Review of economics and statistics, 2000, 82.1: 1-11.

[15] Gani, Azmat. Governance and foreign direct investment links: evidence from panel data estimations. Applied economics letters, 2007, 14.10: 753-756.

[16] Zeshan, Anwar; Talat, Afza. Impact of Governance Indicators on FDI Inflows: Empirical Evidence from Pakistan. Caspian Journal of Applied Sciences Research, 2014, 3.9.

[17] Zidi, Ahmed; Ali, Tarek Ben. Foreign Direct Investment (FDI) and Governance: The Case of MENA. Journal of Research in Business, Economics and Management, 2016, 5.3: 598-608.

[18] Şahin, Dilek. MENA ülkelerinde kurumsal kalite ve ekonomik büyüme ilişkisinin analizi. İktisadi Yenilik Dergisi, 2018, 5.1: 1-9.

[19] Mengistu, Alemu Aye; Adhikary, Bishnu Kumar. Does good governance matter for FDI inflows? Evidence from Asian economies. Asia Pacific business review, 2011, 17.3: 281-299.

[20] Ay, Ahmet; Kizilkaya, Oktay; Akar, Tuba. Gelişmekte olan ülkelerde yolsuzluk ve demokrasi'nin DYY üzerindeki etkisi: ampirik bir inceleme. 2016.

[21] Canare, Tristan. The effect of corruption on foreign direct investment inflows: Evidence from a panel of Asia-Pacific countries. In: The changing face of corruption in the Asia Pacific. Elsevier, 2017. p. 35-55.

[22] Nur, Hayriye Başçı; Dilber, İlkay. Gelişmekte olan ülkelerde doğrudan yabancı yatırımları belirleyen temel unsurlar. Dokuz Eylül Üniversitesi İktisadi İdari Bilimler Fakültesi Dergisi, 2017, 32.2: 15-45.

[23] Al-Sadig, Ali. “FDI Inflows and Corruption." Cato Journal 29(1).2009, 267-94.

[24] Epaphra, Manamba; Massawe, John. The effect of corruption on foreign direct investment: A panel data study. Turkish Economic Review, 2017, 4.1: 19-54.

[25] Sabir, Samina; Rafique, Anum; Abbas, Kamran. Institutions and FDI: evidence from developed and developing countries. Financial Innovation, 2019, 5.1: 1-20.

[26] Masron, Tajul Ariffin; Abdullah, Hussin. Institutional quality as a determinant for FDI inflows: evidence from ASEAN. World Journal of Management, 2010, 2.3: 115-128.

[27] Özşahin, Şerife. Kurumsal kalite doğrudan yabancı yatırımlar için ne kadar önemli? Türkiye üzerine ekonometrik bir analiz. Journal of Yaşar University, 2016, 11.44: 251-262. 
[28] Meon, Pierre-Guillaum; SEKKAT, Khalid. Revisiting the relationship between governance and foreign direct investment. 2007.

[29] Saidi, Yosra; Ochi, Anis; Ghadri, Houria. Governance and FDI attractiveness: Some evidence from developing and developed countries. Global Journal of Management and Business Research, 2013.

[30] Shah, M. Ve A. Afridi (2015). "Significance of Good Governance for FDI Inflows in SAARC Countries by." Business \& Economic Review 7(2):31-52.

[31] Bellos, Sotirios; Subasat, Turan. Governance and foreign direct investment: A panel gravity model approach. International Review of Applied Economics, 2012, 26.3: 303-328.

[32] Luu, Hiep Ngoc, et al. The effect of corruption on FDI and its modes of entry. Journal of Financial Economic Policy, 2019.

[33] Cuervo-Cazurra, Alvaro. Who cares about corruption?. Journal of international business studies, 2006, 37.6: 807-822.

[34] Asiedu, Elizabeth; Freeman, James. The effect of corruption on investment growth: Evidence from firms in Latin America, Sub-Saharan Africa, and transition countries. Review of Development Economics, 2009, 13.2: 200-214.

[35] Eren, Murat; Künü, Serkan."Yolsuzluk ve Ekonomik Büyüme İlişkisi: E7 Ülkeleri İçin Bir Uygulama." Pp. 1470-76 in Iğdır International Conference On Multidisciplinary Studies. Iğdır,2018

[36] World Bank Data, https://data.worldbank.org/

[37] Moscone, Francesco; Tosetti, Elisa. A review and comparison of tests of cross-section independence in panels. Journal of Economic Surveys, 2009, 23.3: 528-561.

[38] Hsiao, Cheng; Pesaran, M. Hashem; Pick, Andreas. Diagnostic tests of cross-section independence for limited dependent variable panel data models. Oxford Bulletin of Economics and Statistics, 2012, 74.2: 253-277.

[39] Breusch, Trevor S.; Pagan, Adrian R. A simple test for heteroscedasticity and random coefficient variation. Econometrica: Journal of the econometric society, 1980, 1287-1294.

[40] Pesaran, M. Hashem. General diagnostic tests for cross-sectional dependence in panels. Empirical Economics, 2004, 1-38.

[41] Pesaran, M. Hashem; Ullah, Aman; Yamagata, Takashi. A bias-adjusted LM test of error crosssection independence. The Econometrics Journal, 2008, 11.1: 105-127.

[42] Ünsal, Mehmet Emre. Kamu Harcamaları, Kamu Gelirleri Ve Kamu Borçlarının Ekonomik Büyüme Üzerindeki Etkileri: Oecd Ülkeleri Üzerine Panel Veri Analizi. Sosyal Bilimler Dergisi/Journal of Social Sciences, 2020, 64.

[43] Hsiao, Cheng. Analysis of panel data. Cambridge university press, 1986

[44] Turgut, Ecem; Uçan, Okyay. Yolsuzluğun Vergi Oranları İle Olan İlişkisinin Oecd Ülkeleri Örnekleminde İncelenmesi. Niğde Ömer Halisdemir Üniversitesi Sosyal Bilimler Enstitüsü Dergisi, 2019, 1.3: 1-17. 
[45] Gün, Musa. Cointegration Between Carbon Emission, Economic Growth, And Energy Consumption: A Comparative Study On Georgia And Turkey. International Journal of Economic \& Administrative Studies, 2019, 22.

[46] Tuna, Gülfen.; Öztürk, Mahmut. Piyasa Etkinliğinin Yapisal Kirilmali Birim Kök Testleri İle İncelenmesi: Türkiye Pay Senedi Piyasasi Uygulamasi. Uluslararası Yönetim İktisat ve İşletme Dergisi, 12.12: 548-559.

[47] Dickey, David A.; Fuller, Wayne A. Distribution of the estimators for autoregressive time series with a unit root. Journal of the American statistical association, 1979, 74.366a: 427-431.

[48] Dickey, David A.; Fuller, Wayne A. Likelihood ratio statistics for autoregressive time series with a unit root. Econometrica: journal of the Econometric Society, 1981, 1057-1072.,

[49] Levin, Andrew; Lin, Chien-Fu; Chu, Chia-Shang James. Unit root tests in panel data: asymptotic and finite-sample properties. Journal of econometrics, 2002, 108.1: 1-24.

[50] IM, Kyung So; Pesaran, M. Hashem; Shin, Yongcheol. Testing for unit roots in heterogeneous panels. Journal of econometrics, 2003, 115.1: 53-74.

[51] Maddala, G.S. Ve Shaowen Wu. “Comparative Study of Unit Root Tests With Panel Data and a New Simple Test", Oxford Bulletin of Economics and Statistics, Special Issue,1999, 61:631-652.

[52] Choi, In. Unit root tests for panel data. Journal of international money and Finance, 2001, 20.2: 249-272.

[53] Ersin, İrfan; Karakeçe, Ercan. Analysis of the effects of macroeconomic factors on entrepreneurship: An application on E7 countries. In: Handbook of research on decision-making techniques in financial marketing. IGI Global, 2020. p. 412-428.

[54] Gülmez, Ahmet; Yardimcioğlu, Fatih. OECD Ülkelerinde Ar-Ge Harcamaları ve Ekonomik Büyüme İlişkisi: Panel Eşbütünleşme ve Panel Nedensellik Analizi (1990-2010). Maliye Dergisi, 2012, 163.1: 335-353.

[55] Kalkavan, Hakan; Ersin, Irfan. Determination of factors affecting the South East Asian crisis of 1997 probit-logit panel regression: The South East Asian crisis. In: Handbook of research on global issues in financial communication and investment decision making. IGI Global, 2019. p. 148-167.

[56] Yüksel, Serhat. The impacts of research and development expenses on export and economic growth. International Business and Accounting Research Journal, 2017, 1.1: 1-8.

[57] Engle, Robert F.; Granger, Clive WJ. Co-integration and error correction: representation, estimation, and testing. Econometrica: journal of the Econometric Society, 1987, 251-276.

[58] Pedroni, Peter. Critical values for cointegration tests in heterogeneous panels with multiple regressors. Oxford Bulletin of Economics and statistics, 1999, 61.S1: 653-670.

[59] Kiliç, Ramazan; Aslan, Volkan. Yenilenebilen ve yenilenemeyen enerjinin iktisadi büyüme üzerindeki etkisi: 28 OECD ülkesi üzerine ampirik bir çalışma. Eskişehir Osmangazi üniversitesi İ̈BF dergisi, 2017, 12.1: 1-12.

[60] Pedroni, Peter. Fully modified OLS for heterogeneous cointegrated panels. In: Nonstationary panels, panel cointegration, and dynamic panels. Emerald Group Publishing Limited, 2001.

[61] Resmi Gazete, https://www.resmigazete.gov.tr/eskiler/2006/10/20061002-1.htm 